\title{
Hubungan Amalan Pengurusan Keselamatan dengan Pematuhan Keselamatan Pekerjaan di Jabatan Bomba dan Penyelamat Malaysia
}

\author{
(Relationship between Safety Management Practices and Job Safety Compliance in Fire and Rescue \\ Department Malaysia) \\ Chandrakantan Subramaniam \\ Md Lazim Mohd Zin \\ (Pusat Pengajian Pengurusan, Kolej Perniagaan, Universiti Utara Malaysia) \\ Siti Rohani Nadir \\ (Akademi Bomba dan Penyelamat Malaysia)
}

\begin{abstract}
ABSTRAK
Kajian ini bertujuan untuk menguji hubungan antara amalan pengurusan keselamatan dengan tingkah laku pematuhan keselamatan pekerjaan. Enam dimensi amalan pengurusan keselamatan adalah komitmen pengurusan, latihan keselamatan, penglibatan pekerja, komunikasi dan maklum balas, peraturan dan prosedur serta dasar promosi keselamatan. Bagi mencapai objektif kajian, sebanyak 270 set soal selidik telah diedarkan kepada pegawai bomba gred KB17 di 9 buah balai bomba di Selangor. Analisis regresi mendapati bahawa komitmen pihak pengurusan, latihan keselamatan dan peraturan, dan prosedur keselamatan mempunyai hubungan yang signifikan dengan pematuhan keselamatan pekerjaan. Manakala faktor-faktor lain iaitu penglibatan pekerja, dasar promosi keselamatan, dan komunikasi dan maklum balas tidak mempunyai hubungan yang signifikan dengan pematuhan keselamatan pekerjaan. Kertas ini turut membincangkan implikasi dan limitasi kajian, dan cadangan untuk kajian susulan.
\end{abstract}

Kata kunci: Pengurusan keselamatan; pematuhan keselamatan pekerjaan; kemalangan pekerjaan; Jabatan Bomba dan Penyelamat Malaysia

\section{ABSTRACT}

This study is intended to examine the relationship between work safety practices and employee compliance of workplace safety. The dimensions of work safety practices include management commitment, safety training, employee involvement, communication and feedback, safety rules and procedures, and safety promotional policies. To achieve the research objective, 270 questionnaires were distributed to the fire officers of grade KB17 from 9 fire departments in Selangor. The regression analysis indicated that management commitment, safety training, and safety rules and procedures are positively related to compliance with safety behavior. Meanwhile employee involvement, safety promotional policies, and communication and feedback are not significantly related to compliance with safety behavior. This paper also discussed the implications and limitations of this study and directions for future research.

Keywords: Security management; occupational safety compliance; occupational accidents; Malaysian Fire and Rescue Department

\section{PENGENALAN}

Kemalangan dan kecederaan di tempat kerja adalah isu yang masih menjadi kebimbangan organisasi. Di Malaysia, umumnya kesedaran mengenai keselamatan dan kesihatan pekerjaan telah menunjukkan peningkatan dari tahun ke tahun. Bermula dengan penguatkuasaan AKKP 1994, majikan dan pekerja mula menyedari peranan dan tanggungjawab masing-masing dalam memastikan hazad di tempat kerja dikenal pasti, ditaksir dan dikawal. Namun keadaan ini masih tidak menjamin tahap keselamatan pekerjaan berada di tahap memuaskan memandangkan kadar kemalangan yang berlaku dalam kalangan pekerja masih agak tinggi pada setiap tahun. Seperti yang ditunjukkan di Jadual 1, sebilangan besar kemalangan pekerjaan yang berlaku telah mengakibatkan kematian dalam kalangan pekerja dan ini menunjukkan bahawa keselamatan serta tahap pematuhan keselamatan di tempat kerja adalah masih rendah.

Bilangan kemalangan pekerjaan mengikut sektor di Malaysia juga membimbangkan. Seperti yang ditunjukkan di Jadual 2, sektor pembuatan merekodkan jumlah kemalangan pekerjaan yang tertinggi iaitu 17,569 kes, diikuti dengan sektor perdagangan (5,279 kes), sektor hartanah, penyewaan dan perniagaan (4,781 kes) dan sektor pembinaan (4,665 kes). Kes kemalangan pekerjaan yang melibatkan kematian, hilang upaya sementara dan hilang upaya kekal juga menunjukkan bahawa sektor pembuatan terus mencatatkan kes tertinggi berbanding dengan sektor-sektor lain. Ini dapat dilihat berdasarkan statistik yang menunjukkan sebanyak 133 kes kematian, 15,409 kes hilang upaya sementara dan 3,397 kes hilang upaya kekal didaftarkan dalam sektor pembuatan. Kemalangan dan kematian dalam kalangan pekerja 
JADUAL 1. Jumlah Kemalangan Pekerjaan dan Kematian di Malaysia bagi Tahun 1998 hingga 2010

\begin{tabular}{lcc}
\hline Tahun & Bilangan Kemalangan & Bilangan Kematian \\
\hline 1998 & 85,338 & 1046 \\
1999 & 92,074 & 912 \\
2000 & 95,006 & 1004 \\
2001 & 85,229 & 958 \\
2002 & 81,810 & 858 \\
2003 & 73,858 & 822 \\
2004 & 69,132 & 846 \\
2005 & 61,182 & 773 \\
2006 & 58,321 & 733 \\
2007 & 56,339 & 755 \\
2008 & 54,133 & 981 \\
2009 & 55,186 & 663 \\
2010 & 57,639 & 660 \\
\hline
\end{tabular}

Sumber: Pertubuhan Keselamatan Sosial (PERKESO) 2012

mengakibatkan kerugian besar kepada negara. Manakala kos tersembunyi akibat kemalangan adalah 8 hingga 36 kali lebih besar daripada kos langsung, dan ini menunjukkan bahawa kemalangan yang berlaku boleh mengakibatkan kerugian berbilion-bilion ringgit kepada negara. Pastinya ini juga mengakibatkan syarikat mengalami kerugian bagi menampung kos seperti kehilangan pekerja, kehilangan waktu bekerja, pembaikan atau penggantian harta dan peningkatan dalam caruman insurans.

Data yang ditunjukkan dalam Jadual 2 juga mendapati bahawa kadar kemalangan dan kematian pekerja sektor awam turut berada pada tahap yang tinggi. Hasil pengauditan yang dijalankan oleh Jabatan Keselamatan dan Kesihatan Pekerjaan (JKKP) terhadap Sistem Pengurusan
Keselamatan dan Kesihatan sektor perkhidmatan awam dari tahun 2007 hingga 2009 turut mendapati bahawa 30\% hingga $40 \%$ sektor perkhidmatan awam masih berada di tahap D dan E iaitu tahap keselamatan dan kesihatan yang tidak memuaskan. Ini bermakna penjawat awam terdedah kepada risiko kemalangan di tempat kerja dan memerlukan kawalan serta sistem keselamatan yang sewajarnya daripada pihak majikan dan pekerja.

Banyak kajian sebelum ini menunjukkan bahawa banyak kes kemalangan yang berlaku berpunca daripada ketidakpatuhan terhadap peraturan keselamatan pekerjaan (Cox \& Cheyne 2000; Glendon \& Litherland 2001; Mearns, Whitaker \& Flin 2003). Pematuhan keselamatan ditakrifkan sebagai sejauh mana pekerja bertingkah laku bagi mematuhi mana-mana peraturan keselamatan, akta atau kod amalan keselamatan seperti dalam garis panduan yang ditetapkan (Vinodkumar \& Bhasi 2010). Pematuhan keselamatan dicapai apabila pekerja melaksanakan kerjakerja berdasarkan peraturan keselamatan berkaitan dan biasanya bekerja dalam cara yang tidak membahayakan (Kelloway \& Francis 2008). Menurut Griffin dan Neal (2006), tingkah laku pematuhan merujuk kepada tindakan atau aktiviti pekerja dalam mewujudkan atau mengekalkan persekitaran selamat di tempat kerja seperti melaksanakan kerja mengikut prosedur, undangundang dan peraturan ditetapkan serta memakai peralatan perlindungan peribadi bagi mengelakkan berlakunya kemalangan. Misalnya, Garavan dan O'Brien (2001) mendapati bahawa tingkahlaku pekerja yang tidak selamat adalah punca yang menyebabkan berlakunya kemalangan di tempat kerja. Misalnya, pekerja akan melakukan kerja secara tidak selamat kerana prosedur kerja yang tidak lengkap dan mereka tidak diberi latihan keselamatan

JADUAL 2. Jumlah Kemalangan Pekerjaan dan Kematian Mengikut Sektor di Malaysia tahun 2010

\begin{tabular}{|c|c|c|c|c|}
\hline Sektor & $\begin{array}{c}\text { Bilangan } \\
\text { Kemalangan } \\
\text { Dilaporkan }\end{array}$ & $\begin{array}{c}\text { Hilang } \\
\text { Upaya } \\
\text { Sementara }\end{array}$ & $\begin{array}{l}\text { Hilang } \\
\text { Upaya } \\
\text { Kekal }\end{array}$ & Kematian \\
\hline Pertanian, perhutanan dan perikanan & 2,561 & 2,185 & 367 & 26 \\
\hline Perlombongan dan kuari & 370 & 300 & 69 & 6 \\
\hline Pembuatan & 17,569 & 15,409 & 3,397 & 133 \\
\hline Perkhidmatan elektrik, gas, air dan kebersihan & 643 & 482 & 136 & 2 \\
\hline Pembinaan & 4,665 & 3,910 & 815 & 88 \\
\hline Perdagangan & 5,279 & 4,510 & 981 & 58 \\
\hline Perdagangan runcit & 4,158 & 3,489 & 631 & 56 \\
\hline Penginapan dan perkhidmatan makanan \& minuman & 1,856 & 1,522 & 287 & 20 \\
\hline Pengangkutan dan penyimpanan & 3,642 & 3,074 & 760 & 50 \\
\hline Kewangan dan insurans & 840 & 672 & 218 & 7 \\
\hline Hartanah, penyewaan dan perniagaan & 4,781 & 4,049 & 923 & 60 \\
\hline Pentadbiran awam dan pertahanan / keselamatan & 4,496 & 3,613 & 850 & 99 \\
\hline Pendidikan & 274 & 215 & 52 & 8 \\
\hline Kesihatan dan kerja sosial & 960 & 823 & 186 & 7 \\
\hline Komuniti, sosial dan persendirian & 320 & 265 & 64 & 2 \\
\hline Aktiviti badan dan pertubuhan luar wilayah & 206 & 161 & 42 & 0 \\
\hline Aktiviti yang tidak didefinisikan & 6 & 1 & 2 & 0 \\
\hline JUMLAH & 57,639 & 48,804 & 10,554 & 660 \\
\hline
\end{tabular}

Sumber: Pertubuhan Keselamatan Sosial (PERKESO), 2012 
yang menepati dengan keperluan pekerjaan (Kelloway \& Francis 2008).

Teori Penyebab Kemalangan Domino yang berdasarkan dokumen tuntutan insurans oleh Heinrich menyatakan bahawa kesilapan manusia merupakan penyumbang tertinggi kepada kemalangan pekerjaan iaitu sebanyak $85 \%$ hingga 95\% (Goetsch 2008). Ini jelas menunjukkan bahawa pematuhan keselamatan adalah amat penting dalam mengurangkan kemalangan di tempat kerja dan ianya turut berkait rapat dengan amalan pengurusan yang dilaksanakan di dalam organisasi. Amalan pengurusan keselamatan merupakan dasar, strategi, prosedur dan aktiviti-aktiviti yang dilaksanakan oleh pihak pengurusan bagi meningkatkan keselamatan pekerja-pekerja mereka (Fernandez-Muniz 2007). Labadova (2004) menganggap amalan pengurusan keselamatan sebagai subsistem dalam keseluruhan pengurusan organisasi dan direka untuk mengawal bahaya yang boleh menjejaskan kesihatan dan keselamatan pekerja. Menurut Cooper dan Philips (2004), amalan pengurusan keselamatan pekerjaan yang cekap dapat memastikan pulangan yang tinggi kepada organisasi dan meningkatkan produktiviti. Sebaliknya, pengabaian isu keselamatan dan kesihatan akan menyebabkan majikan terpaksa menanggung kos seperti pampasan pekerja dan kos perubatan, kos penyiasatan kemalangan, dan kos perundangan.

Beberapa orang penyelidik menyatakan bahawa amalan pengurusan keselamatan memainkan peranan penting dalam membentuk iklim keselamatan dan seterusnya mempengaruhi tahap pematuhan keselamatan dalam organisasi (Cooper \& Philips 2004; Dedobbeleer \& Beland 1998; Griffin \& Neal 2006). Seo (2005) melihat amalan pengurusan sebagai komitmen pengurusan, sokongan penyelia, sokongan rakan sekerja dan penyertaan peringkat pekerja. Vredenburgh (2002) pula menambah baik dimensi amalan keselamatan pekerjaan dengan mengambil kira aspek penglibatan pekerja, latihan keselamatan, sistem ganjaran, komitmen pengurusan dan komunikasi serta maklum balas sebagai amalan pengurusan keselamatan dalam kajiannya di hospital. Glendon dan McKenna (1995) melihat amalan budaya keselamatan dari segi komunikasi yang efektif, pembelajaran organisasi yang baik, fokus organisasi terhadap keselamatan dan kesihatan dan fokus luaran. Menurut Turner (1991), antara langkah bagi memupuk budaya keselamatan termasuklah penghargaan, peranan pengurusan dan polisi.

Menyedari pentingnya amalan pengurusan keselamatan pekerjaan dalam menangani masalah kemalangan dalam kalangan pegawai bomba, maka kajian ini perlu dilakukan bagi menunjukkan kepentingan amalan pengurusan keselamatan dalam meningkatkan kesedaran pematuhan keselamatan di tempat kerja. Ini adalah kerana bidang tugas pegawai bomba sering berhadapan dengan risiko kemalangan, dan terdedah dengan bahaya, kecederaan dan kematian (Chee-Fai, Ranjit \& Mohd Rizal 2012; Sharifah et al. 2012). Menurut Chee-Fai et al. (2012), pegawai bomba perlu bekerja dalam masa yang panjang dan tidak menentu, dan persekitaran kerja yang tidak kondusif seperti suhu yang tinggi, berhabuk, dan kawasan udara berkelembapan rendah. Manakala Sharifah et al. (2012) pula menjelaskan bahawa $76.2 \%$ kecederaan kecil semasa bertugas berlaku dalam kalangan pegawai bomba terjadi kerana tuntutan masa bekerja yang tidak menentu. Situasi ini menyebabkan pegawai bomba mudah berasa letih, dan ini boleh meningkatkan kadar kecederaan. Persekitaran kerja yang sebegini memerlukan pegawai bomba sentiasa peka dengan aspek keselamatan bagi mengurangkan risiko kecederaan dan kemalangan semasa bertugas. Justeru itu, penekanan kepada pelaksanaan amalan pengurusan keselamatan yang efektif adalah penting untuk dikaji, dan sejauh mana amalan ini mempunyai pengaruh terhadap pematuhan keselamatan pekerjaan. Berdasarkan kajian-kajian amalan pengurusan keselamatan yang dijalankan sebelum ini (Cox \& Cheyne 2000; Coyle, Sleeman \& Adams 1995; Flin et al. 2000; Glendon \& Litherland 2001; Varonen \& Mattila 2000; Vredenburgh 2002; Williamson et al. 1997), maka pengkaji memilih enam dimensi amalan pengurusan keselamatan iaitu (1)komitmen pihak pengurusan, (2) latihan keselamatan, (3) penglibatan pekerja, (4) komunikasi dan maklum balas keselamatan, (5) peraturan dan prosedur keselamatan, dan (6) dasar promosi keselamatan sebagai pembolehubah bebas kajian. Keenam-enam amalan pengurusan keselamatan tersebut seterusnya diuji untuk mengenal pasti hubungannya dengan tingkah laku pematuhan keselamatan pekerjaan.

Perbincangan kajian akan diteruskan mengikut urutan berikut. Seksyen seterusnya mengulas kajian-kajian lepas yang berkaitan dengan isu yang dikemukakan dalam kajian ini. Ini diikuti dengan seksyen yang menjelaskan kaedah penyelidikan, seksyen yang melapor dapatan, seksyen yang membincangkan dapatan kajian dan menyimpulkannya, dan akhirnya seksyen yang membincangkan implikasi hasil kajian.

\section{ULASAN KAJIAN LEPAS}

Komitmen pihak pengurusan adalah tanggungjawab atau keprihatinan yang ditunjukkan oleh pihak pengurusan atasan terhadap kepentingan keselamatan, kesedaran terhadap amalan keselamatan, pemeriksaan keselamatan, peruntukan pemakaian peralatan keselamatan dan cara bagaimana pihak pengurusan menegaskan kepentingan amalan keselamatan terhadap pekerja. Hofmann (1996) mendapati bahawa komitmen pengurusan keselamatan merupakan faktor utama yang memberi kesan kepada kejayaan program-program keselamatan organisasi. Komitmen pihak pengurusan dilihat berdasarkan aktiviti keselamatan yang dijalankan, tingkah laku serta percakapan mereka (Hofmann 1996). Berdasarkan persepsi tersebut, pekerja percaya bahawa keselamatan adalah penting dalam organisasi (Griffin \& Neal 2006). Dalam persekitaran yang berisiko tinggi seperti industri bahan kimia, komitmen 
pengurusan telah dibuktikan berjaya meningkatkan tahap keselamatan dalam organisasi (Cox \& Flin 1998; Flin et al. 2000; Cox \& Cheyne 2000).

Latihan keselamatan merujuk kepada program latihan yang disediakan kepada pekerja merangkumi kaedah dan prosedur keselamatan, tindak balas terhadap situasi kecemasan dan penilaian terhadap situasi yang membahayakan di tempat kerja. Syarikat-syarikat yang mempunyai kadar kemalangan yang rendah didapati memberikan latihan keselamatan yang baik kepada pekerja (Zohar 1980). Program latihan yang sistematik dan komprehensif dapat membantu pekerja memahami dan meningkatkan sistem keselamatan dan kesihatan yang berkualiti (Vredenburgh 2002). Davies dan Tomasin (1996) pula menyatakan bahawa latihan keselamatan yang berkesan dapat meningkatkan tahap pematuhan keselamatan seseorang semasa melaksanakan kerja.

Penglibatan pekerja merujuk kepada peluang yang diberikan oleh pihak pengurusan kepada pihak pekerja dalam memberikan pendapat dan membuat keputusan berkaitan isu-isu keselamatan serta penyertaan pekerja dalam jawatankuasa keselamatan. Doke (1997) menyatakan bahawa jawatankuasa keselamatan yang diwakili oleh pihak majikan dan golongan pekerja dapat menyumbang kepada amalam budaya keselamatan. Ini konsisten dengan dapatan beberapa orang penyelidik yang menunjukkan bahawa penglibatan pekerja merupakan satu faktor amalan pengurusan keselamatan yang berkesan dalam meningkatkan pematuhan keselamatan pekerjaan dalam kalangan pekerja di organisasi (Dedobbeleer \& Beland 1998; Goetsch 2008; Lee 1998; Cox \& Cheyne 2000). Manakala Flynn (1994) mendapati penglibatan aktif pekerja dalam aktiviti keselamatan dan kesihatan berjaya memupuk kesedaran keselamatan yang lebih baik selain digunakan sebagai strategi efektif untuk mendapatkan komitmen pekerja dalam meningkatkan tingkah laku pematuhan keselamatan.

Komunikasi dan maklum balas keselamatan merujuk kepada penyaluran maklumat dan keterbukaan bagi membincangkan isu-isu keselamatan antara golongan pekerja dengan pengurusan. Komunikasi yang berkesan dan mudah difahami oleh pekerja dapat membantu mewujudkan komitmen pekerja untuk mematuhi peraturan dan melaksanakan kerja dengan selamat (Glendon \& Mckenna 1995). Ini kerana komunikasi yang jelas tentang isu-isu keselamatan di antara pengurusan, penyelia dan tenaga kerja merupakan amalan pengurusan yang berkesan untuk meningkatkan keselamatan di tempat kerja (Cohen, Smith \& Anger 1979; Cox \& Cheyne 2000; Goetch 2008; Vredenburgh 2002; Zohar 1980).

Peraturan dan prosedur keselamatan adalah berkaitan penyediaan dan penguatkuasaan tatacara, prosedur atau garispanduan yang perlu dipatuhi bagi meningkatkan keselamatan di tempat kerja. Kajian keselamatan yang dijalankan oleh Cox dan Cheyne (2000) dalam kalangan pekerja pesisir pantai mendapati bahawa penyediaan peraturan dan prosedur keselamatan adalah faktor penting dan mempunyai hubungan yang signifikan dengan kadar kemalangan. Ini kerana organisasi yang kerap menyebarkan dasar dan peraturan keselamatan kepada pekerja boleh menimbulkan kesedaran dan seterusnya mereka lebih cenderung untuk bertingkah laku dan mematuhi aspek keselamatan semasa bekerja.

Dasar promosi keselamatan merujuk kepada polisi keselamatan pekerjaan dan usaha organisasi untuk menyampaikan dan mempromosikan maklumat berkaitan dengan aspek keselamatan di tempat kerja. Menurut Ab. Aziz dan Intan (2002), organisasi hendaklah sentiasa mengambil tanggungjawab terhadap keselamatan pekerja dengan mempromosikan isu keselamatan pekerjaan. Kajian oleh Cox dan Cheyne (2000) berkaitan persepsi pekerja terhadap keselamatan mendapati bahawa penyebaran maklumat keselamatan secara meluas dalam organisasi membolehkan semua pekerja dan mereka yang terlibat dengan pekerjaan tersebut mengetahui isu keselamatan yang dihadapi, dan mengetahui tindakan yang sesuai yang perlu diambil jika berlaku sebarang masalah berhubung dengan keselamatan dan kesihatan pekerjaan. Berdasarkan perbincangan di atas, enam hipotesis berikut dikemukakan.

$\mathrm{H}_{1}$ Komitmen pihak pengurusan mempunyai hubungan yang signifikan dengan pematuhan keselamatan pekerjaan.

$\mathrm{H}_{2}$ Latihan keselamatan mempunyai hubungan yang signifikan dengan pematuhan keselamatan pekerjaan.

$\mathrm{H}_{3}$ Penglibatan pekerja mempunyai hubungan yang signifikan dengan pematuhan keselamatan pekerjaan.

$\mathrm{H}_{4} \quad$ Komunikasidanmaklumbalas keselamatanmempunyai hubungan yang signifikan dengan pematuhan keselamatan pekerjaan.

$\mathrm{H}_{5}$ Peraturan dan prosedur keselamatan mempunyai hubungan yang signifikan dengan pematuhan keselamatan pekerjaan.

$\mathrm{H}_{6}$ Dasar promosi keselamatan mempunyai hubungan yang signifikan dengan pematuhan keselamatan pekerjaan.

\section{KERANGKA KAJIAN}

Kajian ini bertujuan mengenal pasti tahap amalan pengurusan keselamatan di Jabatan Bomba dan Penyelamat Malaysia (JBPM) serta menentukan hubungan antara amalan pengurusan keselamatan dengan pematuhan keselamatan pekerjaan. Dimensi amalan pengurusan keselamatan ini merangkumi komitmen pihak pengurusan yang menerangkan sejauh mana pihak pengurusan komited kepada memastikan pekerja bekerja dalam keadaan yang selamat. Dimensi latihan keselamatan melihat kepada amalan pengurusan dalam menyediakan latihan keselamatan yang relevan kepada konteks pekerjaan manakala dimensi penglibatan pekerja merujuk kepada kebolehan pihak pengurusan mendapatkan penglibatan pekerjaan dalam isu-isu berkaitan keselamatan pekerjaan. Komunikasi dan maklum balas merujuk kepada 
amalan pihak pengurusan menyediakan suasana yang menggalakkan komunikasi antara kedua-dua pihak majikan dan pekerja dalam membincangkan isu keselamatan pekerjaan. Dimensi peraturan dan prosedur pula merujuk kepada amalan pihak pengurusan mereka bentuk serta melaksanakan peraturan serta prosedur keselamatan untuk memastikan tempat kerja itu selamat. Manakala dimensi terakhir dasar promosi keselamatan melihat kepada amalan pihak pengurusan dalam mempromosikan keselamatan tempat kerja dalam kalangan pekerjanya. Kerangka kajian dipamerkan dalam Rajah 1.

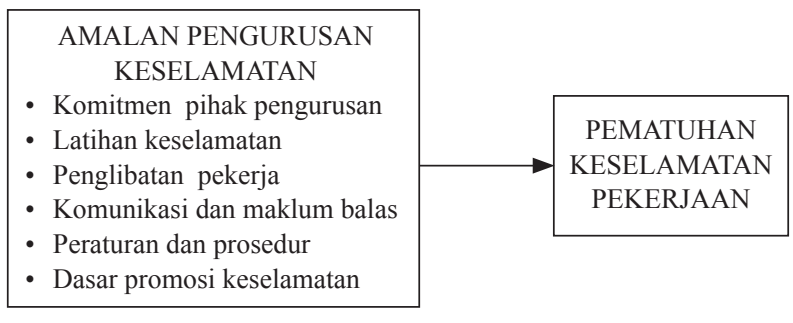

RAJAH 1. Kerangka Kajian

\section{METODOLOGI KAJIAN}

\section{SAMPEL KAJIAN DAN PROSEDUR}

Dalam kajian ini, teknik persampelan rawak berlapis digunakan kerana kajian ini melibatkan pemilihan responden secara berasingan bagi setiap subkumpulan dalam populasi. Selain itu, pengkaji juga boleh memastikan setiap sub kumpulan (balai bomba) mempunyai bilangan responden yang homogenius. Responden yang dipilih

JADUAL 3. Profil Responden

\begin{tabular}{lcc}
\hline \multicolumn{1}{c}{ Item } & Bilangan & Peratus \\
\hline Jantina & & \\
Lelaki & 220 & 90.2 \\
$\quad$ Perempuan & 24 & 9.8 \\
Umur & & \\
30 tahun ke bawah & 107 & 78.5 \\
31 hingga 40 tahun & 87 & 35.7 \\
41 hingga 50 tahun & 31 & 12.7 \\
Lebih 50 tahun & 19 & 7.8 \\
Bangsa & & \\
Melayu & 221 & 90.6 \\
India & 12 & 4.9 \\
Cina & 1 & 0.4 \\
Lain-lain & 10 & 4.1 \\
Taraf pendidikan & & \\
SRP / PMR & 21 & 8.6 \\
SPM / STPM & 186 & 76.2 \\
Diploma & 34 & 13.9 \\
Ijazah & 3 & 1.2 \\
Pengalaman kerja & & \\
Kurang 5 tahun & 39 & 16.0 \\
6-10 tahun & 102 & 41.8 \\
11-20 tahun & 86 & 35.2 \\
Lebih 21 tahun & 17 & 7.0 \\
\hline
\end{tabular}

melibatkan seramai 270 pegawai gred KB17 dari 9 buah balai bomba kategori A di Selangor. Sebanyak 270 borang soal selidik telah diedarkan kepada responden dan kesemuanya telah dikembalikan. Namun terdapat beberapa outliers dan akhirnya hanya seramai 244 responden sahaja dipilih sebagai sampel kajian. Taburan keseluruhan responden kajian ditunjukkan dalam Jadual 3. Analisis profil responden menunjukkan bahawa majoriti responden adalah lelaki $(90.2 \%)$, berbangsa Melayu (90.6\%), berumur 30 tahun ke bawah (78.5\%), berpendidikan SPM/STPM (76.2\%) dan mempunyai tempoh perkhidmatan antara 6 hingga 10 tahun (41.8\%).

\section{PENGUKURAN}

\section{Amalan Pengurusan Keselamatan}

Amalan pengurusan keselamatan merujuk kepada praktis, peranan dan fungsi yang berhubung kait dengan tindakan memastikan tempat kerja itu berada pada tahap yang selamat (Kirwan 1998). Ia sering dikaitkan sebagai satu subsistem dalam pengurusan organisasi secara menyeluruh dan dijalankan melalui sistem pengurusan keselamatan organisasi dengan bantuan pelbagai amalan pengurusan keselamatan. Sistem pengurusan keselamatan adalah mekanisme yang diintegrasi dalam organisasi (Labodova 2004) dan direka bentuk untuk mengawal hazad yang boleh memudaratkan keselamatan dan kesihatan pekerja. Amalan pengurusan keselamatan adalah polisi, strategi, prosedur, dan aktiviti yang dilaksana dan dipatuhi oleh pengurusan dalam sesebuah organisasi dengan tujuan menjamin keselamatan pekerja. Ia merupakan elemen penting yang memastikan pengurusan keselamatan di sesebuah organisasi berada pada tahap yang memuaskan serta direka bentuk untuk mematuhi perundangan keselamatan pekerjaan sedia ada di sesebuah negara. Tahap amalan di sesebuah organisasi boleh dilihat melalui pelbagai inisiatif dan program yang dilaksanakan oleh pihak pengurusan dan ini dapat dilihat secara nyata oleh warga organisasi tersebut. Instrumen kajian yang dibangunkan oleh Vinodkumar dan Bhasi (2010) digunakan dalam kajian ini. Ia melibatkan enam dimensi amalan pengurusan keselamatan iaitu (1) komitmen pihak pengurusan, (2) latihan keselamatan, (3) penglibatan pekerja, (4) komunikasi dan maklum balas keselamatan, (5) peraturan dan prosedur keselamatan, dan (6) program keselamatan. Sebanyak 35 soalan telah dibentuk bagi mengukur persepsi pekerja berkaitan amalan pengurusan yang dijalankan di tempat kerja. Soalan berkisar kepada sejauh mana amalan pengurusan diberi perhatian dalam meningkatkan kesedaran dan tahap pematuhan keselamatan di tempat kerja. Pengukuran bagi setiap soalan adalah menggunakan 5 mata Skala Likert iaitu bermula dari 1 (sangat tidak setuju) hingga 5 (sangat setuju). Analisis kebolehpercayaan dan pekali Cronbach Alpha digunakan sebagai alat bagi menentukan darjah konsistensi setiap dimensi tersebut. Nilai darjah konsistensi berdasarkan kajian terdahulu yang dilaksanakan oleh Vinodkumar dan Bhasi (2010) adalah dari 0.64 hingga 0.86. 


\section{Pematuhan Keselamatan Pekerjaan}

Pematuhan keselamatan pekerjaan merujuk kepada tahap kepatuhan pekerja terhadap peraturan dan undang-undang keselamatan pekerjaan atau tindakan pekerja untuk melakukan pekerjaannya secara selamat. Pengukuran bagi pematuhan keselamatan pekerjaan ini juga berdasarkan kajian oleh Vinodkumar dan Bhasi (2010). Setiap soalan diukur dengan menggunakan 5 mata Skala Likert iaitu bermula dari 1 (sangat tidak setuju) hingga 5 (sangat setuju). Terdapat 7 soalan yang dibentuk bagi mengukur pematuhan tersebut dan responden dikehendaki memberikan penarafan berdasarkan kekerapan mereka melaksanakan tugas mengikut peraturan yang ditetapkan. Darjah konsistensi bagi pembolehubah pematuhan keselamatan adalah $\alpha=0.76$.

\section{DAPATAN KAJIAN}

\section{ANALISIS KORELASI PEARSON DAN REGRESI BERGANDA}

Dapatan kajian dianalisis menggunakan analisis korelasi pearson dan analisis regresi berganda bagi mengkaji hubungan antara pembolehubah bebas amalan pengurusan keselamatan dengan pembolehubah bersandar iaitu pematuhan keselamatan pekerjaan. Seperti yang dilaporkan dalam Jadual 4, kenam-enam amalan pengurusan keselamatan mempunyai hubungan yang positif dengan tingkahlaku pematuhan keselamatan pekerjaan. Latihan keselamatan memperoleh skor tertinggi $(\mathrm{r}=.675, p<.01)$, dan diikuti oleh komitmen pihak pengurusan $(\mathrm{r}=.592, p<.01)$, peraturan dan prosedur keselamatan $(\mathrm{r}=.565, p<.01)$, komunikasi dan maklumbalas keselamatan $(\mathrm{r}=.541, p<.01)$, penglibatan pekerja $(\mathrm{r}=.513, p<.01)$ dan yang terendah adalah dasar promosi keselamatan $(\mathrm{r}=.389, p<.01)$.

Analisis regresi digunakan bagi mengkaji hubungan antara amalan pengurusan keselamatan dengan tingkah laku pematuhan keselamatan. Hubungan ini akan menentukan jenis amalan pengurusan keselamatan yang lebih memberikan kesan signifikan kepada tingkah laku pematuhan. Jadual 5 melaporkan nilai $R^{2}$ yang menunjukkan bahawa $51.1 \%$ perubahan dalam pembolehubah pematuhan keselamatan pekerjaan boleh dijelaskan dengan amalan pengurusan keselamatan. Keputusan analisis regresi ini juga menunjukkan hanya tiga daripada enam dimensi amalan keselamatan pekerjaan iaitu latihan keselamatan $(\beta=0.467, p<.01)$, komitmen pihak pengurusan $(\beta=0.249, p<.05)$ dan peraturan dan prosedur keselamatan $(\beta=0.179, p<.05)$ mempunyai hubungan yang signifikan dengan pematuhan keselamatan. Manakala tiga dimensi amalan keselamatan pekerjaan lagi iaitu komunikasi dan maklum balas keselamatan, penglibatan pekerja dan dasar promosi keselamatan tidak mempunyai hubungan signifikan dengan pematuhan keselamatan.

JADUAL 5. Ringkasan Keputusan Analisis Regresi

\begin{tabular}{lc}
\hline Pembolehubah Bebas & $\begin{array}{c}\text { Pembolehubah bersandar: } \\
\text { Pematuhan keselamatan }\end{array}$ \\
\hline Komitmen pengurusan & $.249^{*}$ \\
Latihan keselamatan & $.467^{*}$ \\
Penglibatan pekerja & $.034^{*}$ \\
Komunikasi & $-.093^{*}$ \\
Peraturan & $.179^{*}$ \\
Dasar promosi & $-.022^{*}$ \\
Statistiks: & $43.353^{* *}$ \\
$F$ value & .523 \\
$R^{2}$ & .511 \\
Adjusted $R^{2}$ & \\
\hline Nota $* \mathrm{p}<.05, * * \mathrm{p}<.01$ &
\end{tabular}

\section{PERBINCANGAN DAN KESIMPULAN}

Kajian ini bertujuan untuk mengenal pasti hubungan antara amalan pengurusan keselamatan dengan tingkah laku pematuhan keselamatan pekerjaan. Kajian ini mendapati bahawa amalan-amalan pengurusan seperti latihan keselamatan, komitmen pihak pengurusan serta peraturan dan prosedur keselamatan mempengaruhi pematuhan keselamatan. Apa yang jelas, dapatan ini dapat memberikan input kepada pihak JBPM untuk meningkatkan lagi tahap pematuhan keselamatan pekerjaan, maka tiga dimensi pembolehubah peramal iaitu latihan keselamatan, komitmen pihak pengurusan serta peraturan dan prosedur keselamatan hendaklah diutamakan. Ini kerana telah terbukti dalam kajian ini

JADUAL 4. Min, Korelasi dan Cronbach Alpha bagi Pembolehubah Amalan Pengurusan Keselamatan dan Pembolehubah Pematuhan Keselamatan Pekerjaan

\begin{tabular}{|c|c|c|c|c|c|c|c|c|c|}
\hline Pembolehubah & Min & 1 & 2 & 3 & 4 & 5 & 6 & 7 & Cronbach $\alpha$ \\
\hline Komitmen pengurusan & 3.93 & - & & & & & & & 0.870 \\
\hline Latihan keselamatan & 4.08 & $.618 * *$ & - & & & & & & 0.778 \\
\hline Penglibatan pekerja & 3.79 & $.761 * *$ & $.552 * *$ & - & & & & & 0.873 \\
\hline Komunikasi & 3.74 & $.758 * *$ & $.680 * *$ & $.717 * *$ & - & & & & 0.774 \\
\hline Peraturan & 3.99 & $.615 * *$ & $.603 * *$ & $.626 * *$ & $.648 * *$ & - & & & 0.818 \\
\hline Dasar promosi & 3.46 & $.528 * *$ & $.485 * *$ & $.690 * *$ & $.635 * *$ & $.490 * *$ & - & & 0.852 \\
\hline Pematuhan & 4.35 & $.592 * *$ & $.675 * *$ & $.513 * *$ & $.541^{* *}$ & $.565 * *$ & $.389 * *$ & - & 0.800 \\
\hline
\end{tabular}

Nota: $* * p<.01$ 
bahawa ketiga-tiga elemen tersebut memberi impak yang besar ke atas pematuhan keselamatan. Responden menganggap bahawa latihan keselamatan, komitmen pihak pengurusan serta peraturan dan prosedur sebagai amalan pengurusan yang penting dalam meningkatkan tahap kesedaran mereka terhadap keselamatan. Indikator ini menunjukkan bahawa pegawai bomba menunjukkan perasaan puas hati yang tinggi terhadap ketiga-tiga amalan tersebut dan secara tidak langsung mereka akan menghargainya dengan mempraktikkannya dalam pelaksanaan tugas kebombaan. Ini secara tidak langsung dapat mengurangkan kadar kemalangan, kemalangan nyaris dan kecederaan akibat kemalangan pekerjaan (Hayes et al. 1988; Zohar 1980).

Latihan keselamatan mencatatkan nilai pekali $\beta$ yang tertinggi (0.647) dan memberikan petunjuk kepada JBPM bahawa untuk meningkatkan tahap pematuhan keselamatan pekerjaan, maka aspek latihan perlu diberi keutamaan. Dapatan ini menyokong dapatan kajian oleh Vredenburgh (2002) bahawa latihan keselamatan yang diberikan kepada pekerja dapat meningkatkan kesedaran terhadap keselamatan dan mematuhi prosedur kerja yang selamat. Apabila semua pekerja mengambil bahagian dalam latihan keselamatan, maka terdapat beberapa kebaikan iaitu sesuatu kerja tersebut dapat dijalankan dengan berkualiti dan mewujudkan kesedaran terhadap keselamatan. Davies dan Tomasin (1996) juga menyatakan bahawa latihan keselamatan yang berkesan merupakan antara elemen asas yang menjadikan pematuhan keselamatan lebih efektif dalam pengurusan keselamatan dan kesihatan pekerjaan. Latihan dan pengetahuan keselamatan yang mencukupi dapat meningkatkan kemahiran bekerja dan pada masa yang sama mengingatkan mereka supaya sentiasa mengamalkan budaya kerja yang selamat dalam rutin pekerjaan mereka. Ini disokong oleh Mullen (2004) yang berpendapat bahawa proses sosialisasi melalui program latihan yang bersesuaian perlu diberikan kepada pekerja-pekerja baru agar mereka terdedah kepada input positif yang boleh memandu mereka ke arah kerja yang selamat berdasarkan prosidur ditetapkan. Pendedahan kepada pelbagai kepakaran dan kemahiran juga menjadikan mereka lebih berpengetahuan untuk mematuhi segala peraturan pekerjaan serta melaksanakan tugas secara selamat (Vredenburgh 2002). Ini konsisten dengan pandangan bahawa program-program yang berorientasikan keselamatan boleh melahirkan pekerja yang mempunyai budaya kerja selamat kerana mereka mempunyai kemahiran dalam memahami situasi kecemasan dan risiko di tempat kerja (Cooper \& Philips 2004; Lee 1998; Zohar 1980).

Sebagai sebuah agensi penyelamatan yang sentiasa berhadapan dengan risiko kecederaan dan kematian, pihak pengurusan JBPM juga sentiasa memberikan komitmen yang tinggi dan perhatian yang serius terutama dalam memastikan semua arahan dan prosedur keselamatan mencukupi serta dipraktikkan semasa bertugas. Usaha dilakukan dari masa ke semasa bagi meningkatkan tahap keselamatan anggota seperti mengadakan tindakan pembetulan, menyiasat kemalangan yang berlaku, pengawalan hazard yang baik dan menyediakan peralatan pelindung diri yang mencukupi serta meningkatkan interaksi antara pihak pengurusan dengan pekerja. Dapatan ini menyokong kajian yang dibuat oleh Yule, Flin dan Murdy (2007) yang menyatakan bahawa pihak pengurusan memainkan peranan penting dalam memastikan keselamatan di tempat kerja. Ini konsisten dengan kajian yang mendapati bahawa pihak pengurusan yang memberikan komitmen yang tinggi dan memperuntukkan sejumlah kewangan bagi aktiviti keselamatan dan kesihatan akan menjadikan pekerja lebih bertanggungjawab untuk mematuhi peraturan dan undangundang (Mearns, Whitaker \& Flin 2003).

Pada masa yang sama, JBPM sentiasa mewajibkan setiap anggota yang terlibat dalam operasi kebombaan mematuhi prosedur operasi piawai (SOP) yang ditetapkan selain memakai peralatan kelengkapan diri yang sempurna bagi tujuan perlindungan diri daripada ancaman bahaya. Turner (1991) turut bersetuju bahawa peraturan dan prosedur keselamatan yang diterapkan di tempat kerja mampu menggalakkan keprihatinan semua pekerja terhadap pematuhan keselamatan. Penguatkuasaan peraturan dan prosedur kerja yang berterusan oleh JBPM memberikan peringatan kepada pekerja untuk sentiasa melaksanakan kerja secara selamat dan mengikut tatacara ditetapkan. Kajian ini menyokong kajian terdahulu yang mendapati bahawa penyediaan peraturan dan prosedur keselamatan mempunyai hubungan yang signifikan dengan pematuhan keselamatan dan kadar kemalangan yang berlaku (Cox \& Cheyne 2000; Mearns et al. 2003).

Namun begitu, amalan pengurusan dari segi penglibatan pekerja, komunikasi dan maklum balas keselamatan serta dasar promosi keselamatan tidak mempengaruhi tingkah laku terhadap pematuhan keselamatan pekerjaan di JBPM. Dapatan ini tidak memberikan sokongan empirikal kepada hipotesis dan tidak selaras dengan kajian yang dilaksanakan sebelum ini (Cox \& Cheyne 2000; Dedobbeleer \& Beland 1998; Goetch 2008; Lee 1998; Vredenburgh 2002; Zohar 1980). Walaupun pada dasarnya JBPM telah mewujudkan Jawatankuasa Keselamatan dan Kesihatan Pekerjaan yang menggabungkan peranan antara pihak pengurusan dengan pekerja, namun kewujudan jawatankuasa ini mungkin tidak dapat memperlihatkan hubungan yang kolektif antara pihak pekerja dengan pengurusan JBPM dalam membincangkan isu berkaitan keselamatan pekerjaan. Faktor seperti jurang komunikasi yang wujud di antara pihak pengurusan tertinggi dengan pekerja bawahan juga mungkin mengakibatkan kesukaran untuk mendapatkan persetujuan bersama dalam sesuatu keputusan berkaitan keselamatan. Sebagai sebuah badan beruniform, aliran komunikasi yang berlaku lebih terarah kepada bentuk atas - bawah yang mana pihak pengurusan lebih banyak membuat keputusan dan arahan, manakala pekerja hanya perlu mengikut arahan yang dikeluarkan oleh pihak pengurusan. 
Komunikasi dan maklum balas antara pihak pengurusan dengan pekerja bawahan mungkin tidak berlaku sebagaimana yang diharapkan. Walaupun JBPM sentiasa berusaha untuk bersikap terbuka dan mengalualukan semua pendapat tentang isu-isu keselamatan di tempat kerja, namun ruang yang disediakan tersebut mungkin masih tidak mencukupi. Pegawai bawahan mungkin berasakan terdapat jurang yang besar antara pekerja dengan pihak pengurusan tertinggi, dan ini telah membataskan aliran komunikasi secara langsung. Hirarki jawatan dalam JBPM yang berdasarkan pangkat dan perbezaan peranan daripada segi pemberi dan penerima arahan mungkin menyebabkan aliran maklumat keselamatan yang ingin disampaikan tidak sampai kepada pekerja di peringkat bawahan. Situasi sebaliknya juga mungkin berlaku sekiranya pekerja di peringkat bawahan ingin menyampaikan maklumat berkaitan dengan keselamatan dan kesihatan pekerja kepada pegawai atasan JBPM. Situasi ini mungkin berlaku disebabkan oleh kurangnya medium yang sesuai untuk menyampaikan maklumat, kurangnya sokongan daripada pengurus pertengahan, dan rasa bimbang pekerja terhadap kerahsiaan maklumat yang disampaikan kepada pengurus atasan.

Dasar promosi keselamatan yang tidak memberikan kesan terhadap pematuhan keselamatan pekerjaan mungkin berpunca daripada pelbagai faktor seperti faktor individu (pekerja) atau faktor organisasi (JBPM) itu sendiri dalam melaksanakan dasar promosi keselamatan. Sikap pekerja yang kurang memandang serius aspek keselamatan serta tidak mengendahkan aktiviti yang menjurus kepada amalan pematuhan keselamatan pekerjaan mungkin disebabkan mereka berasa telah cukup memahami dan mengamalkan ciri-ciri keselamatan berdasarkan peralatan atau kelengkapan perlindungan diri yang dipakai serta tatacara operasi yang rutin dijalankan. Pendekatan promosi keselamatan yang digunakan oleh JBPM seperti seminar atau bengkel keselamatan mungkin tidak lagi sesuai bagi menimbulkan kesedaran ke arah peningkatan pematuhan keselamatan pekerjaan. Pendekatan baru seperti pertandingan kempen kemalangan sifar antara negeri dan pertandingan-pertandingan yang berobjektif mungkin boleh dilaksanakan untuk menyalurkan pengetahuan dan input terkini kepada kakitangan. Insentif tertentu kepada pekerja, pasukan atau negeri yang berjaya mengurangkan kadar kemalangan di tempat kerja juga mungkin boleh difikirkan kerana ia dapat memotivasikan pekerja terus melaksanakan kerja secara selamat, mengurangkan kemalangan serta mematuhi peraturan operasi sepernuhnya semasa menjalankan tugas (Turner 1991).

\section{IMPLIKASI KAJIAN}

Kajian ini menyumbang kepada pengkayaan susastera dan aplikasi secara praktikal khususnya mengenai pematuhan keselamatan di tempat kerja dalam beberapa aspek.
Secara teorinya, kajian ini berjaya memberi gambaran baharu dari segi input dan perspektif memandangkan ianya dijalankan di organisasi beruniform yang terlibat dalam tugas berisiko tinggi. Berbanding kajian terdahulu yang banyak dilaksanakan di negara barat, kajian ini telah menghasilkan keputusan yang sedikit berbeza yang secara tidak langsung menunjukkan perbezaan pemikiran antara timur dan barat. Kajian ini juga selari dengan konsep yang diutarakan oleh teori pertukaran sosial (Blau 1964). Mengikut teori ini seseorang individu akan masuk ke dalam hubungan pertukaran dengan orang lain kerana individu itu merasakan dia akan memperoleh imbalan. Dengan kata lain ia melihat antara perilaku dengan lingkungan terdapatnya hubungan yang saling mempengaruhi. Dalam konteks kajian ini apabila amalan pengurusan keselamatan yang baik dilaksanakan oleh pihak pengurusan organisasi, pekerja akan merasakan dia memperoleh imbalan. Ini akan mencetus hubungan saling mempengaruhi oleh pekerja dengan pematuhan keselamatan yang akan memberikan keuntungan kepada syarikat melalui penurunan kos tuntutan akibat kemalangan tempat kerja, ketidakhadiran serta kadar lantik henti.

Daripada aspek praktikal pula, kajian ini bukan sahaja memberi sumbangan dari sudut akademik tetapi juga dapat memberikan manfaat serta menambahkan pengetahuan kepada pengkajian bidang pengurusan sumber manusia dari segi amalan pengurusan keselamatan pekerjaan. Organisasi seperti JBPM perlu memberi keutamaan kepada amalan pengurusan keselamatan khususnya daripada segi latihan keselamatan, komitmen pihak pengurusan, dan peraturan dan prosedur keselamatan untuk meningkatkan dan memperbaiki tahap pematuhan keselamatan dalam kalangan pekerja. Kajian ini juga dapat menyediakan maklumat kepada Jawatankuasa Keselamatan dan Kesihatan Pekerjaan bagi tujuan pembentukan strategi dan program berkaitan selain memberikan input kepada Majlis Keselamatan dan Kesihatan Pekerjaan bagi tujuan penambahbaikan akta sedia ada.

Perbincangan dapatan kajian ini adalah lebih menyeluruh sekiranya beberapa perkara berikut diambil kira untuk kajian akan datang. Pertamanya, dicadangkan lebih banyak kajian perlu dijalankan untuk mengesahkan lagi hubungan latihan keselamatan, komitmen pihak pengurusan serta peraturan dan prosedur keselamatan terhadap pematuhan keselamatan pekerjaan. Ini kerana skop kajian ini hanya tertumpu kepada pegawai yang bertugas di bahagian operasi di JBPM Selangor sahaja dan bilangan responden yang dipilih juga agak kecil iaitu 244 orang. Kajian seumpama ini boleh diperluaskan ke negeri-negeri lain serta melibatkan pegawai dari pelbagai gred bagi memberikan darjah konsistensi yang lebih tinggi. Fokus kajian ini juga hanya melihat hubungan antara amalan pengurusan terhadap aspek pematuhan keselamatan pekerjaan. Impak daripada pematuhan keselamatan pekerjaan itu sendiri tidak disentuh iaitu adakah ia berjaya menurunkan jumlah kemalangan dalam kalangan kakitangan JBPM atau sebaliknya. Kajian akan 
datang juga boleh mempertimbangkan faktor-faktor lain di tempat kerja yang boleh menyumbang kepada tingkah laku pematuhan keselamatan dalam kalangan pekerja seperti faktor demografi, motivasi, personaliti individu atau pengetahuan sebagai moderator atau mediator. Selain itu, aspek kesihatan mungkin boleh dikaji dengan lebih mendalam memandangkan kajian ini hanya memfokuskan kepada aspek keselamatan. Kajian berkaitan kesihatan pekerja masih kurang dilaksanakan di negara ini walaupun ia sebenarnya amat penting bagi membolehkan organisasi seperti JBPM mengenal pasti sejauh mana kesan pendedahan kepada bahan kimia, asap, debu, toksid dan sebagainya ke atas tahap kesihatan kakitangannya. Tambahan pula terdapat kajian di barat yang menunjukkan bahawa ramai pegawai bomba mengalami masalah kesihatan akibat terdedah kepada pelbagai asap, debu dan sebagainya.

Secara keseluruhannya, kajian ini telah berjaya menunjukkan kepentingan amalan pengurusan keselamatan yang berkesan dalam mempengaruhi mereka untuk menunjukkan tingkah laku dan sikap yang selamat di tempat kerja dan seterusnya mematuhi peraturan pekerjaan. Walaupun hanya tiga daripada enam hipotesis yang berjaya dibuktikan, namun dapatan kajian ini telah menyumbang kepada pengkayaan ilmu pengurusan keselamatan dan berpotensi untuk dikembangkan kepada lain-lain agensi berkaitan.

\section{RUJUKAN}

Ab. Aziz Yusof \& Intan Osman. 2002. Pengurusan Sumber Manusia: Konsep, Isu dan Pelaksanaan. Petaling Jaya: Prentice Hall.

Blau, P. M. 1964. Exchange and Power in Social Life. New York: John Wiley \& Sons.

Chee-Fai, T., Ranjit, S. S. S. \& Moh Rizal Alkahari . 2012. Water pressure loss analysis of mobile machine for fire fighting purpose. International Journal of Soft Computing and Engineering 2(1): 470-473.

Cohen, A., Smith, M. \& Anger, W. 1979. Self-protective measures against workplace hazards. Journal of Safety Research 11: 121-131.

Cox, S. J. \& Cheyne, A. J. T. 2000. Assessing safety culture in offshore environments. Safety Science 34: 111-129.

Cox, S. \& Flin, R. 1998. Safety culture: philosopher's stone or man of straw? Work and Stress 12(3): 189-201.

Cheyne, A., Cox, S., Oliver, A. \& Tomas, J. 1998. Modelling safety climate in the prediction of levels of safety activity. Work and Stress 12: 255-271.

Cooper, M. D. \& Philips, R. A. 2004. Exploratory analysis of the safety climate and safety behaviour relationship. Journal of Safety Research 35(5): 497-512.

Coyle, I., Sleeman, S. \& Adams, D. 1995. Safety climate. Journal of Safety Research 22: 247-254.

Davies, V. J. \& Tomasin, K. 1996. Construction Safety Handbook. London: Thomas Telford Publishing, Thomas Telford Services Ltd

Dedobbeleer, N. \& Beland, F. 1998. Is risk perception one of the dimensions of safety climate? In Occupational Injury: Risk Prevention and Intervention, edited by A. Freyer \& A Williamson, 73-81. London: Taylor and Francis.
Doke, L. 1997. Training and precision are brewing a powerful safety culture. Journal of Safety Management. May 1997: 10-13.

Fernandez-Muniz. 2007. Safety management system: Development and validation of a multidimensional scale. Journal of Loss Prevention in the Process Industries 20: $52-68$.

Flin, R., Mearns, K., O’Connor, P. \& Bryden, R. 2000. Measuring safety climate: identifying the common features. Safety Science 34: 177-193.

Flynn, G. 1994. Company strive for yawn-free safety awareness. Personal Journal 73(7): 12-20.

Garavan, T.N. \& O'Brien, F. 2001. An investigation into the relationship between safety climate and safety behaviours in Irish organisations. Irish Journal of Management 22(1): 141-170.

Glendon, A.I. \& Litherland, D.K. 2001. Safety climate factors, group differences and safety behavior in road construction. Safety Science 39: 157-188.

Glendon, A.I. \& McKenna, E.F. 1995. Human Safety and Risk Management. London: Chapman Hall.

Goetsh, D.L. 2008. Occupational Safety and Health for Technologist Engineers and Managers. 6th edition. New Jersey: Pearson Prentice Hall.

Griffin, M.A. \& Neal, A. 2006. Perceptions of safety at work: a framework for linking safety climate to safety performance, knowledge, and motivation. Journal of Occupational Health and Psycholog 5(3): 347-358.

Hayes, B.E., Perander, J., Smecko, T. \& Trask, J. 1998. Measuring perceptions of workplace safety. development and validation of the work safety scale. Journal of Safety Research 29: 145-161.

Hofmann, D. A. 1996. A cross-level investigation of factors influencing unsafe behaviour and accidents. Personnel Psychology 49(2): 307-339.

Kelloway, E. K. \& Francis, L. 2008. Management of Occupational Health \& Safety. Edisi Ke-4. Ontario: Nelson Education ltd.

Kes kemalangan di tempat kerja. Diakses pada 21 Januari 2012 dari http://www.perkeso.gov.my/ ms/berita-perkeso/591762.

Kirwan, B. 1998. Safety management assessment and task analysis - a missing link? In Safety Management: The Challenge of Change, edited by A. Hale \& M. Baram. Elsevier, Oxford.

Labodova, A. 2004. Implementing integrated management systems using a risk analysis based approach. Journal of Cleaner Production 12: 571-580.

Lee, T. 1998. Assessment of safety culture at a nuclear reprocessing plant. Work and Stress 12: 217-237.

Mearns, K., Whitaker, S. M. \& Flin, R. 2003. Safety climate, safety management practice and safety performance in offshore environments. Safety Science 41: 641-680.

Mullen, J. 2004. Investigating factors that influence individual safety behavior at work. Journal of Safety Research 35: 275-285.

Neal, A., Griffin, M. A. \& Hart, P. M. 2000. The impact of organizational climate on safety climate and individual behavior. Safety Science 34: 99-109.

Seo, D. C. 2005. An explicative model of unsafe work behaviour. Safety Science 43: 187-211.

Sharifah Osman, Ismail Bahari, Kadir Arifin, Wan Mohd Nor Ibrahim \& Chen, T. F. 2012. Accident risk indices of Malaysia's firefighters working in 12 and 24 hours shift 
works. Journal of Occupational Safety and Health 9: 25-30.

Turner, B. A. 1991. The development of a safety culture Chemistry and Industry 4: 241-243.

Varonen, U. \& Mattila, M. 2000. The safety climate and its relationship to safety practices, safety of work environment and occupational accidents in eight woodprocessing companies. Accident Analysis and Prevention 32: 761769.

Vredenburgh, A. G. 2002. Organizational safety: Which management practices are most effective in reducing employee injury rates?. Journal of Safety Research 33: 259-276.

Vinodkumar, M. N. \& Bhasi, M. 2010. Safety management practices and safety behaviour: Assessing the mediating role of safety knowledge and motivation. Accident Analysis and Prevention 42(6): 2082-2093.

Williamson, A. M., Feyer, A., Cairns, D. \& Biancotti, D. 1997. The development of a measure to safety climate: The role of safety perceptions and attitudes. Safety Science 25: 15-27.

Yule, S., Flin, R. \& Murdy, A. 2007. The role of management \& safety climate in preventing risk-taking at work. International Journal of Risk Assessment and Management 7: 137-151.
Zohar, D. 1980. Safety climate in industrial organizations: Theoretical and applied implications. Journal of Applied Psychology 65: 96-102.

Chandrakantan Subramaniam (penulis koresponden) Pusat Pengajian Pengurusan

Kolej Perniagaan

Universiti Utara Malaysia

06010 Sintok, Kedah

E-mel: chandra@uum.edu.my

Md Lazim Mohd Zin

Pusat Pengajian Pengurusan

Kolej Perniagaan

Universiti Utara Malaysia

06010 Sintok, Kedah

E-mel: lazim@uum.edu.my

Siti Rohani Nadir

Akademi Bomba dan Penyelamat Malaysia

Jalan Padang Tembak

44000 Kuala Kubu Bharu, Selangor

E-mel: srbn@bomba.gov.my 